chronic ingrowing toenail with thickened nail: use phenol cauterisation of lateral nail matrix ${ }^{4}$ or wedge procedure. ${ }^{9}(4)$ Onychogryphosis: use phenol cauterisation of whole germinal matrix.

Dr F B Wallace stimulated the initial design of the gutter treatment, and we are also indebted to Mr D E Cross, of Portex Ltd, for help with the prototype development and the production of a sterile kit. Our thanks go to Mrs D Weightman for statistical advice; and $\mathrm{Mr} \mathrm{D}$ Hammersley, medical artist, Newcastle University, and Mr G Lythe, medical artist, Queen's Medical Centre, Nottingham, for the illustrations. Finally, we are grateful to the consultant surgeons in Newcastle for referring patients for treatment, and for their help.

\section{References}

${ }^{1}$ Murray, W R, and Bedi, B S, British fournal of Surgery, 1975, 62, 409. ${ }^{2}$ Lloyd-Davies, R W, and Brill, G C, British fournal of Surgery, 1963, 50, 592.
3 Zadik, F R, fournal of Bone and foint Surgery, 1950, 32B, 66.

${ }^{4}$ Ross, W R, Surgical Clinics of North America, 1969, 49, 1499.

${ }^{5}$ Dumble, E, Pathakji, G S, and Weston, P A M, in preparation.

6 Wallace, W A, and Milne, D D, fournal of Bone and Foint Surgery, 1978, 60B, 437.

7 Wallace, W A, paper read to the North of England Surgical Society, June 1978.

${ }^{8}$ Lancet, 1975, 2, 167.

${ }^{9}$ Fowler, A W, British fournal of Surgery, 1958, 45, 382.

10 Lloyd-Davies, R W, British Fournal of Surgery, 1963, 50, 44.

11 Fowler, A W, Lancet, 1975, 2, 453.

12 Dagnall, J C, Lancet, 1975, 2, 324.

${ }_{13}$ Murray, W R, Lancet, 1975, 2, 414.

14 Newman, R W, Surgery, Gynecology and Obstetrics, 1949, 89, 638.

${ }_{15}$ Mogull, P, fournal of the National Association of Chiropodists, 1954, 44, 35.

${ }_{16}$ Dagnall, J C, British Chiropody fournal, 1965, 30, 100.

17 Ilfeld, F W, and August, W, Orthopedic Clinics of North America, 1974, 5, 95.

18 Townsend, A C, and Scott, P J, fournal of Bone and Foint Surgery, 1966, 48B, 354 .

(Accepted 11 fune 1979)

\title{
Maternal smoking habits and congenital malformations: a population study
}

\author{
DEWI R EVANS, ROBERT G NEWCOMBE, H CAMPBELL
}

British Medical fournal, 1979, 2, 171-173

\section{Summary and conclusions}

Maternal smoking habits in 67609 singleton pregnancies were examined. The overall incidence of congenital malformations was $2.8 \%$ in both non-smokers and smokers. On analysing congenital defects according to individual systems there was no significant difference in the incidence of malformations according to the number of cigarettes smoked, except for neural tube defects. Further analysis, taking social class into account, showed that neural tube defects were less common in non-smokers in social classes I and II.

This study suggests that maternal smoking does not have teratogenic effects in the offspring, except in the case of neural tube defects, where the effect is at most modest.

\section{Introduction}

Babies of mothers who smoke during pregnancy are more likely to be born small; there is an increased incidence of placental separation, and a small but significant increase in perinatal mortality for every period of gestation. ${ }^{1}$ Little attention has been focused on the possibility of a relation between maternal smoking habit and congenital malformation in the offspring. Cigarette smoking might possibly act as a teratogenic agent.

Welsh National School of Medicine, Cardiff CF4 4XW

DEWI R EVANS, MB, MRCP, lecturer in child health

ROBERT G NEWCOMBE, MA, FSS, statistician, department of medical statistics

H CAMPBELL, FRCP, FFCM, professor of medical statistics
Nicotine crosses the placental barrier. ${ }^{2}$ Smoking by pregnant women substantially raises the carboxyhaemoglobin concentration of fetal blood, ${ }^{3}$ and in pregnant animals a high induced concentration of carboxyhaemoglobin is associated with an increased incidence of congenital malformations in the offspring. ${ }^{4} \mathrm{~N}$-nitroso compounds in cigarette smoke are teratogenic in rats when administered by the respiratory route. ${ }^{5}$

Yerushalmy $^{6}$ and Mulcahy and Knaggs ${ }^{7}$ did not find any differences in congenital malformation that could be accounted for by maternal smoking habits. In a recent study by Kelsey et $a l^{\circ}$ women who smoked 20 or more cigarettes daily had a relative risk of 1.6 for congenital malformations in the offspring compared with non-smokers. This risk was greatest for abnormalities of the digestive system (2.9), heart valves (2.0), and skin (1.9), and neural tube defects and chromosomal abnormalities $(1.8)$, and was independent of other indices including maternal age, social class, marital state, religion, parity, and race. Choi and Klaponski ${ }^{9}$ also noted a probable association between heavy smoking and neural tube defects. In a study of 18000 patients Andrews and $\mathrm{McGarry}^{1}$ found a significant association between maternal smoking and the incidence of cleft lip or palate, or both, and a small non-significant association with gastrointestinal and neural tube defects. They did not analyse their findings according to the number of cigarettes smoked. We analysed the association between maternal cigarette smoking and congenital malformation in the offspring in a large-scale study that included and extended the sample of Andrews and McGarry. We report here our results.

\section{Patients and methods}

A total of 69062 singleton deliveries were recorded in the Cardiff Births Survey during the 12 years 1965-76. These included all deliveries to Cardiff residents and, to supplement the sample size, all deliveries in the city. ${ }^{10}$ The mothers were divided into four groups according to smoking habit: non-smokers, light smokers (1-9 cigarettes per day; including women giving up for part of the pregnancy), moderate smokers (10-19 per day), and heavy smokers (20 or more 
per day). Data on all congenital malformations were divided into the following categories: anencephaly, spina bifida, other abnormalities of the central nervous system; abnormalities of the cardiovascular, gastrointestinal, genitourinary, and skeletal systems; cleft lip or palate, or both; and a miscellaneous group consisting of skin, endocrine, and chromosomal abnormalities.

\section{Results}

We obtained information on the smoking habits of the mother for $67609(97.9 \%)$ of the deliveries studied. Table I shows the overall incidence of congenital defects, which was the same in non-smokers and smokers. Table II shows the incidence of congenital defects in the population according to the particular type of malformation; infants with several malformations contribute to several rows. There was no correlation between smoking habits and malformations of the cardiovascular, gastrointestinal, genitourinary, or skeletal system. There was a slightly higher incidence of cleft lip or palate, or both, in moderate and heavy smokers, although this difference failed to reach significance.

TABLE I-Proportions of babies born with congenital malformation according to maternal smoking habit

\begin{tabular}{lccccc}
\hline & \multicolumn{4}{c}{ No of cigarettes smoked daily } & \multirow{2}{*}{ Total } \\
\cline { 2 - 5 } & None & $1-9$ & $10-19$ & $\geqslant 20$ & \\
\hline $\begin{array}{l}\text { Total No of deliveries } \\
\text { No }\left(\begin{array}{l}\circ \\
\text { def with congenital } \\
\text { defects }\end{array}\right.\end{array}$ & 36752 & 12617 & 12165 & 6075 & 67609 \\
& $1022(2 \cdot 8)$ & $316(2 \cdot 5)$ & $345(2 \cdot 8)$ & $181(3 \cdot 0)$ & $1864(2 \cdot 8)$
\end{tabular}

The only significant associations with smoking related to neural tube defects; the apparent protective effects against malformations of cardiovascular and musculoskeletal systems did not reach significance. The incidence of anencephaly increased steadily from the non-smokers to the heavy smokers $\left(\chi^{2}\right.$ for trend $=5 \cdot 39, \mathrm{df}=1$,

TABLE II-Incidence of congenital malformations per 1000 births according to maternal smoking habit (total numbers of malformations in parentheses)

\begin{tabular}{|c|c|c|c|c|}
\hline & \multicolumn{4}{|c|}{ No of cigarettes smoked daily } \\
\hline & None & $\begin{array}{c}1-9 \\
(\operatorname{light})\end{array}$ & $\begin{array}{c}10-19 \\
\text { (moderate) }\end{array}$ & $\begin{array}{l}\geqslant 20 \\
\text { (heavy) }\end{array}$ \\
\hline $\begin{array}{l}\text { Anencephaly } \\
\text { Spina bifida } \\
\text { Other CNS defects } \\
\text { Cardiovascular system } \\
\text { Gastrointestinal system } \\
\text { Genitourinary system } \\
\text { Musculoskeletal system } \\
\text { Cleft lip or palate, or both } \\
\text { Miscellaneous }\end{array}$ & $\begin{array}{l}1.7(63) \\
2.6(97) \\
4.5(165) \\
3.6(133) \\
1.9(70) \\
4.6(168) \\
11.3(415) \\
1.5(54) \\
2.5(91)\end{array}$ & $\begin{array}{l}1 \cdot 7(21) \\
1 \cdot 5(19) \\
4 \cdot 8(60) \\
2 \cdot 9(36) \\
1 \cdot 7(21) \\
4.5(57) \\
9 \cdot 3(117) \\
1.5(19) \\
1.6(20)\end{array}$ & $\begin{array}{l}2 \cdot 5(30) \\
3 \cdot 1(38) \\
3 \cdot 9(48) \\
3 \cdot 0(37) \\
2 \cdot 6(32) \\
4 \cdot 4(53) \\
9 \cdot 9(120) \\
2 \cdot 2(27) \\
2 \cdot 1(26)\end{array}$ & $\begin{array}{r}3 \cdot 0(18) \\
4 \cdot 0(24) \\
6 \cdot 1(37) \\
2 \cdot 8(17) \\
1.8(11) \\
4 \cdot 9(30) \\
10 \cdot 4(63) \\
1.8(11) \\
3.0(18)\end{array}$ \\
\hline Total births & 36752 & 12617 & 12165 & 6075 \\
\hline
\end{tabular}

CNS $=$ Central nervous system

$P<0.05)$, though neither the trend in smokers alone nor the difference between smokers and non-smokers reached significance. The incidence of spina bifida was lowest in the light smokers, so that the trend in smokers alone was significant $\left(\chi^{2}=10 \cdot 85, P<0.001\right)$, while neither the trend across all four groups nor the difference between all smokers and non-smokers reached significance. Smoking habits and the incidence of neural tube defects are both influenced by social class. ${ }^{11} 12$ Table III shows a further analysis of the incidence of anencephaly and spina bifida in three social-class groups according to maternal smoking habits. The social-class difference for these neural tube defects remained irrespective of smoking habits. In non-smokers the trend was highly significant $\left(\chi^{2}=10.30, \mathrm{df}=1, \mathrm{P}<0.002\right)$, the incidence being $2 \cdot 4 / 1000$ births in social classes I + II compared with $4 \cdot 7$ in social class III and 5.6 in social classes IV + V. The same trend was seen in smokers, the incidences being $3 \cdot 3,4 \cdot 3$, and $6 \cdot 9 / 1000$ births respectively $\left(\chi^{2}=8 \cdot 29, \mathrm{df}=1, \mathrm{P}<0.004\right)$. In social classes $\mathrm{I}$
TABLE III-Incidence of anencephaly and spina bifida per 1000 births according to social class and maternal smoking habits

\begin{tabular}{lcccc}
\hline \multicolumn{5}{c}{ No of cigarettes smoked daily } \\
\cline { 2 - 5 } & None & $1-9$ & $10-19$ & $\geqslant 20$ \\
\hline & Social classes I & and II & & \\
Total No of births & 8863 & 1939 & 1227 & 463 \\
Incidence of anencephaly & $0 \cdot 9$ & $1 \cdot 5$ & $2 \cdot 4$ & $0 \cdot 0$ \\
Incidence of spina bifida & $1 \cdot 5$ & $0 \cdot 5$ & $4 \cdot 1$ & $0 \cdot 0$ \\
& Social class III & & \\
Total No of births & 1853 & 6372 & 6350 & 2957 \\
Incidence of anencephaly & $1 \cdot 5$ & $0 \cdot 6$ & $2 \cdot 5$ & $3 \cdot 4$ \\
Incidence of spina bifida & $3 \cdot 2$ & $1 \cdot 1$ & $2 \cdot 5$ & $5 \cdot 1$ \\
& Social classes IV and V & & \\
Total No of births & 6553 & 2691 & 3236 & 1793 \\
Incidence of anencephaly & $3 \cdot 4$ & $2 \cdot 2$ & 3.1 & $2 \cdot 8$ \\
Incidence of spina bifida & $2 \cdot 3$ & $3 \cdot 3$ & $4 \cdot 9$ & 3.9 \\
& & & & \\
\hline
\end{tabular}

and II the incidence of these neural tube defects was slightly greater in smokers, although the total numbers were small. Interpretation in social class III was complicated by the lower incidence in ligh smokers, a factor not present in the other social classes. In this social class the incidence in heavy smokers was particularly high. The incidence of neural tube defects was extremely high in social classes IV and V irrespective of smoking habits, and although there was no difference between non-smokers and light smokers, defects were slightly more common in moderate and heavy smokers.

\section{Discussion}

Interpreting data relating to a multifactorial condition such as congenital malformation is difficult when considering one possible factor such as cigarette smoking. This difficulty is enhanced when smoking habits are confounded with separate external factors such as social class. In investigating the effect of smoking, the "dose" effect must also be analysed, which means dividing the population into many groups according to the number of cigarettes smoked and requires a large population for adequate statistical interpretation. Some women, aware of medical opposition to cigarette smoking, especially during pregnancy, may perhaps understate the number of cigarettes smoked. Information from non-smokers and heavy smokers may reasonably be assumed to be accurate.

This study provides information on the incidence of congenital malformation in over 67000 neonates. The data were collected prospectively over 12 years and are not influenced by observer bias. Analysis of the incidence of congenital malformations showed no gradient nor any association between cigarette consumptions and a congenital defect of the cardiovascular, gastrointestinal, genitourinary, or skeletal system. The incidence of cleft lip or palate, or both, was slightly higher in moderate and heavy smokers. The apparent lower incidence of congenital malformations in light smokers related only to the numbers of defects in the miscellaneous group of malformations and the incidence of spina bifida in social class III, and may be considered to be a statistical artefact. Neural tube defects were more common in all smokers in social classes I and II, in heavy smokers in social class III, and in moderate and heavy smokers in social classes IV and V. Against the argument that smoking is a substantial factor in the aetiology of neural tube defects is the fact that $52 \%$ of all babies with neural tube defects in this study were born to non-smokers, who constituted $54 \%$ of the participating population.

Interestingly, the population with the highest incidence of neural tube defects was similar to the one that is most likely to smoke, and to smoke heavily; but the conclusion must remain that if maternal cigarette smoking is causally related to neural tube defects in the offspring, it is probably of only modest importance in the aetiology of this condition.

We thank Mrs M A Dauncey for extracting the computerised data. 


\section{References}

1 Andrews, J, and McGarry, J M, Fournal of Obstetrics and Gynaecology of the British Commonwealth, 1972, 79, 1057.

${ }^{2}$ Larson, P S, Haag, H B, and Silvette, H, Tobacco, Experimental and Chemical Studies, p 390. Baltimore, Williams and Williams, 1961.

3 Cole, P V, Hawkins, L H, and Roberts, D, Fournal of Obstetrics and Gynaecology of the British Commonwealth, 1972, 79, 782.

4 Astrup, P, et al, Lancet, 1972, 2, 1220.

5 Magee, P N, Montesano, R, and Pressman, R, Chemical Carcinogens, ed C E Searle, ACS Monograph Series No 173. Washington, American Chemical Society, 1976.
- Yerushalmy, J, American fournal of Obstetrics and Gynecology, 1964, 88, 505.

7 Mulcahy, R, and Knaggs, J F, American Fournal of Obstetrics and Gynecology, 1968, 101, 844 .

${ }^{8}$ Kelsey, J L, et al, fournal of Epidemiology and Community Health, 1978, 32, 102.

${ }^{9}$ Choi, M, and Klaponski, S, Neurology, 1970, 20, 399.

10 Duncan, A S, et al, The Cardiff Births Survey. In preparation.

11 Capoll, P S, Health Trends, 1978, 10, 49.

12 Edwards, J H, British fournal of Social Medicine, 1958, 12, 15.

(Accepted 15 fune 1979)

\title{
Autonomic neuropathy in rheumatoid arthritis
}

\author{
M E EDMONDS, T C JONES, W A SAUNDERS, R D STURROCK
}

British Medical fournal, 1979, 2, 173-175

the heart-rate response to the Valsalva manoeuvre ${ }^{5}$ and beat-tobeat variation in heart rate with respiration. ${ }^{6}$

\section{Summary and conclusions}

Patients with seropositive and seronegative rheumatoid arthritis (RA) and age-matched controls were investigated for the presence of autonomic neuropathy. Significantly more patients with RA had abnormal autonomic function, suggesting that autonomic neuropathy occurs more commonly in RA than hitherto suspected.

The existence of an autonomic neuropathy may be an important complicating factor in rheumatoid disease and may lead to increased morbidity and mortality.

\section{Introduction}

Peripheral neuropathy is a well-described complication of rheumatoid arthritis (RA), ${ }^{1}$ but few reports on autonomic neuropathy exist. In 1963 Kalliomäki et al ${ }^{2}$ showed a deficient sweating response to an intradermal injection of nicotine in patients with RA. In 1965 Bennett and Scott $^{3}$ found areas of deficient sweating corresponding to cutaneous sensory disease in patients with seropositive RA with peripheral neuropathy but did not examine seronegative patients. In three of their patients a deficient sweating response was found in the absence of peripheral neuropathy, suggesting the presence of a lone autonomic neuropathy. We investigated patients with RA by assessing the integrity of their cardiovascular reflexes. The principal investigation comprised monitoring the immediate heart-rate response to standing as described by Ewing et al, ${ }^{4}$ who found that the normal response of an initial tachycardia followed by a relative bradycardia was absent in diabetics with autonomic neuropathy. To test autonomic function further we investigated

University Department of Therapeutics and Rheumatology, Westminster Medical School, St Stephens Hospital, London SW10 9TH

M E EDMONDS, BSC, MRCP, registrar

T C JONES, medical physics technician

W A SAUNDERS, MD, MRCP, senior registrar

R D STURROCK, MD, MRCP, senior lecturer and consultant

\section{Subjects and methods}

We investigated 68 subjects and divided them into four groups: patients with classical and definite RA, ${ }^{7}$ both seropositive and seronegative (mean age 54.6 (range 22-67) years); patients with osteoarthritis (mean age 54.2 (range 42-65) years); old controls (mean age $51 \cdot 0$ (range 41-67) years); and young controls (mean age 24.6 (range 20-28) years). Before any investigations were done each subject was interviewed and had a full clinical examination. Patients receiving drugs influencing cardiac rhythm were excluded. All subjects were normotensive, not anaemic, and not in cardiac failure. The immediate heart-rate response to standing was measured as described by Ewing et $a l .{ }^{4}$ To quantitate the response we calculated the R-R ratio as follows:

$$
\mathrm{R}-\mathrm{R} \text { ratio }=\frac{\mathrm{R}-\mathrm{R} \text { interval at time of maximum bradycardia }}{\mathrm{R}-\mathrm{R} \text { interval at time of maximum tachycardia }}
$$

In our subjects the mean maximum bradycardia occurred 25 beats after standing and the mean maximum tachycardia five beats after standing. In the study of Ewing $e t \mathrm{al}^{4}$ the mean maximum bradycardia occurred 30 beats after standing and the mean maximum tachycardia 15 beats after standing, giving their ratio of 30:15.

The Valsalva manoeuvre was performed in a standardised manner and the heart rate recorded continuously throughout the strain period and for a further 20 seconds. The changes in heart rate were expressed as the ratio of the maximum tachycardia to the maximum bradycardia - that is, the Valsalva ratio. This test was performed on 12 subjects (10 patients with RA and two young controls). Beat-to-beat variation with respiration was recorded by the method of Wheeler and Watkins ${ }^{6}$ using a Cardiac Recorders Cardiorater Type 64 and a Flat Bed Chart Recorder. The subjects were instructed to breathe deeply at a rate of 6-8 breaths/min, and the beat-to-beat variation was calculated by measuring the difference between maximum and minimum heart rates.

\section{Results}

Immediate heart-rate response to standing-Fig 1 shows the heartrate response to standing in the four groups, with a characteristic tachycardia and relative bradycardia most pronounced in the young controls but also present in the group with osteoarthritis and the old controls. The response was least pronounced in the patients with RA. Fig 2 shows the individual R-R ratios in the four groups. The scatter was wide in each group. Ten patients (nine with RA and one old control) had an R-R ratio of one or less-that is, an abnormal value. There was a significant difference in the mean $R-R$ ratio between the 